\title{
Effects of phase-inversion waterborne epoxy resin on properties of cold patch waterborne epoxy emulsified asphalt
}

\author{
Boming Tang ${ }^{1,2}$, Yu Gu${ }^{1}$, Jianming Ling ${ }^{1}$, Lihong $\mathrm{He}^{2}$ and Fan Yang ${ }^{1}$ \\ ${ }^{1}$ Ministry of Education, The Key Laboratory of Road and Traffic Engineering, Tonji University, Shanghai, People's Republic of China \\ ${ }^{2}$ School of Civil Engineering, Chongqing Jiaotong University, Chongqing, People's Republic of China
}

\begin{abstract}
In order to evaluate effects of waterborne epoxy resin prepared by the phase-inversion method (phase-inversion waterborne epoxy resin) on properties of waterborne epoxy emulsified asphalt for cold patch engineering of asphalt pavement, a series of methods for evaluating properties of emulsified asphalt and casting resin were used. Results show that, with an increase in waterborne epoxy resin content, penetration, ductility, surface curing time of waterborne epoxy emulsified asphalt decrease and its adhesion degree, shear strength and bond strength increase. Moreover, its penetration, ductility and adhesion degree remain unchanged when the content of waterborne epoxy resin exceeds $20 \%$, and its shear strength and bond strength increase most remarkably when the content of waterborne epoxy resin increases from $10 \%$ to $20 \%$. The test results are explained by the surface fluorescent micromorphology of cured waterborne epoxy emulsified asphalt that, with the increase in waterborne epoxy resin content, epoxy resin particles firstly appear as segregated spots, and then change from spotted status to clustered status, and the epoxy resin phase gradually becomes a continuous phase. In conclusion, phase-inversion waterborne epoxy resin has effects on properties of the cold patch waterborne epoxy emulsified asphalt, and recommended content of waterborne epoxy resin is $20 \%$.
\end{abstract}

KEYWORDS Pavement engineering; waterborne epoxy emulsified asphalt; phase-inversion; layering method; continuous phase; fluorescent microscope

CONTACT Yu Gu

@guyu8241183@163.com

Received 27 September 2018

\section{Introduction}

As a commonly used cold patch material, emulsified asphalt shows many advantages (Zhang, 2005), but in cold patch applications, it also shows deficiencies such as low bond strength, high thermo-sensitivity and agingresistance. Nevertheless, they have been conventionally modified by different types of modifiers (Al-Sabagh, 2002). As one of these modifiers, waterborne epoxy resin as a new type, which inherits excellent high acid resistance (Abd El-Rahman et al., 2017), mechanical performance (Qian et al., 2012), bond strength and high-temperature stability (Zhang et al., 2017) from epoxy resin, shows advantages like free of tackiness and environmentally friendliness than oil-based epoxy resin (Zhang et al., 2017), so it has been recently revealed as the modifier of emulsified asphalt in cold patch engineering (Zhang et al., 2017; Zhang and He, 2007; Ding et al., 2007; Ding et al., 2011; Shen et al., 2012; Chen and Chen, 2016), and emulsified asphalt modified by waterborne epoxy resin has been studied in recent years.

Zhang and He (2007) studied adhesion and various performances of evaporation residues and durability of emulsified asphalt mixed by the compound of waterborne epoxy resin and styrene-butadiene rubber (SBR), and results reveal that this emulsified asphalt showed better road performances than those of ordinary asphalt emulsion and SBR modified asphalt emulsion. Studies of Ding et al. $(2007$; 2011) show that performances of a cementbased material reinforced by epoxy resin and emulsified asphalt (CAE) were good, especially rutting deformation at high temperature and adhesive strength with steel blocks; furthermore, the microscopic feature of CAE was related to its development of performances. Shen et al. (2012) researched cementation and hardening mechanisms of CAE, and results show that the crosslinked action of the bonding system of asphalt binder and cement hydration products was not obvious, but the bonding system was enhanced by epoxy hardening products, because they were interleaved with cement hydration products, and reinforced asphaltic material.

In the studies of waterborne epoxy resin modified emulsified asphalt, the content of waterborne epoxy resin was a research focus. Ding et al. (2011) fixed the ratio of cement and emulsified asphalt to be 1:1.5, and the ratio of waterborne epoxy resin and solidifiers to be 1:2, varying the ratio of waterborne epoxy resin and emulsified asphalt from 0 to 0.6 , with the interval of 0.2 , to study mechanical properties and pavement performances of CAE. The results show that mechanical properties and high temperature and low temperature performances improved remarkably when the ratio of waterborne epoxy resin and emulsified asphalt increased from 0 to 0.2 , but the improvement was 
limited when the ratio increased from 0.2 to 0.6 . Chen and Chen (2016) analysed effects of waterborne epoxy resin, waterborne curing agent and emulsified asphalt on waterborne epoxy emulsified asphalt and then determined its reasonable formula to be $15 \%$ (the total of waterborne epoxy resin and curing agent). Zhang et al. (2017) studied the influence of content of waterborne epoxy resin on the epoxy SBR modified emulsified asphalt by storage stability test, viscosity test, three fundamental indexes tests and oblique shear test, determining the optimal content of waterborne epoxy resin as $3 \%$.

It can be seen from earlier studies that the difference of optimal content of waterborne epoxy resin is remarkable. Besides the difference of application conditions, one of the reasons may be the difference of the property of waterborne epoxy resin, which depends on its preparing method. There are mainly three preparing methods of waterborne epoxy resin: mechanical method, phase-inversion method and chemical grafting method. Waterborne epoxy resin prepared by the phase-inversion method has particle size of $1 \mu \mathrm{m}$ $2 \mu \mathrm{m}$, which is uniformly distributed, and the preparing process is relatively simple and inexpensive.

In this paper, the phase-inversion method was used to prepare waterborne epoxy resin, and blended with emulsified asphalt to prepare waterborne epoxy emulsified asphalt, without any other additives such as cement or SBR. The surface fluorescent micromorphology of cured waterborne epoxy emulsified asphalt was firstly studied. Then, because epoxy resin shows thermosetting property, which is different from other modifiers of emulsified asphalt (Yu et al., 2009), test methods of casting resin were referred to evaluate effects of the phase-inversion waterborne epoxy resin on waterborne epoxy emulsified asphalt. The methods included surface curing time test and adhesion degree test, which were widely used to evaluate properties of the waterborne epoxy resin coating. Moreover, for the cold patch waterborne epoxy emulsified asphalt is eventually used as a pavement material, effects of the phase-inversion waterborne epoxy resin on waterborne epoxy emulsified asphalt were also evaluated by test methods of modified emulsified asphalt, which includes penetration and ductility of emulsion residue, shear strength and bond strength, respectively, and of which an advised sample-prepare method of penetration and ductility of emulsified asphalt residue - "layering method" was tried. Furthermore, the test results were analysed by the surface fluorescent micromorphology of cured waterborne epoxy emulsified asphalt, combined with referred opinions of earlier studies.

\section{Material, methods and calculation}

\subsection{Materials}

The epoxy emulsifier was a segmented copolymer synthesised by epoxy resin (WSR618, E-51) and polyethylene glycol (PEG4000) through nucleophilic addition reaction, initiated by potassium persulfate (KPS). The molecule ratio of the E-51 epoxy resin and PEG4000 was $1: 1$. Through nucleophilic addition reaction, the terminal hydroxyl group of PEG was introduced into molecule chain of epoxy resin, and then the non-ionic epoxy emulsifier with the hydrophilic group and the lipophilic group on the both sides of the molecule chain was produced.

The waterborne epoxy resin was prepared by the phase-inversion method (Zhang et al., 2001; Yang et al., 2001) by the above epoxy emulsifier and the E-51 epoxy resin in laboratory. Properties of the waterborne epoxy resin were tested, and the results are shown in Table 1.

Table 1. Properties of waterborne epoxy resin.

\begin{tabular}{|c|c|c|c|}
\hline Content & Test method & Requirement & Test result \\
\hline Appearance & Observation & $\begin{array}{c}\text { Milky viscous } \\
\text { fluid }\end{array}$ & $\begin{array}{c}\text { Milky viscous } \\
\text { fluid }\end{array}$ \\
\hline $\begin{array}{c}\text { Epoxy equivalent } \\
\text { (Solids) }\end{array}$ & $\begin{array}{c}\text { Hydrochloric } \\
\text { acid-acetone } \\
\text { method }\end{array}$ & $180-230$ & 192 \\
\hline Solid content (\%) & GB/1725 - 1989 & $60.0 \pm 2.0$ & 59.8 \\
\hline $\begin{array}{c}\text { Viscosity } \\
\left(\text { mpa } / 25^{\circ} \mathrm{C}\right)\end{array}$ & $\begin{array}{c}\text { NDJ - 79 rotary } \\
\text { viscometer }\end{array}$ & $20-2000$ & 24.1 \\
\hline Specific gravity & $\begin{array}{c}\text { GB1756 - 79 } \\
\text { pH value }\end{array}$ & $1.03-1.10$ & 1.08 \\
\hline Acidometer & $2.0-7.0$ & 7.0 \\
\hline Particle size $(\mu \mathrm{m})$ & $\begin{array}{c}\text { SALD - 310 } \\
\text { laser particle } \\
\text { size analyser }\end{array}$ & $1-2$ & 1.308 \\
\hline $\begin{array}{c}\text { Stability, } 3000 \mathrm{rpm}, \\
30 \text { mins }\end{array}$ & $\begin{array}{c}\text { Centrifugal } \\
\text { method }\end{array}$ & Unstratified & Unstratified \\
\hline Stability, 40 days & $\begin{array}{c}\text { Storage method } \\
\text { Unstratified }\end{array}$ & Unstratified \\
\hline
\end{tabular}

A modified triethylenetetramine was used as the waterborne curing agent of the epoxy resin, received from the market. The properties of the waterborne curing agent are shown in Table 2.

Table 2. Properties of waterborne curing agent of epoxy resin.

\begin{tabular}{|c|c|c|c|}
\hline Content & Test method & Requirement & Test result \\
\hline Appearance & Observation & $\begin{array}{c}\text { Yellowish } \\
\text { uniform fluid }\end{array}$ & $\begin{array}{c}\text { Yellowish } \\
\text { uniform fluid }\end{array}$ \\
\hline $\begin{array}{c}\text { Active hydrogen } \\
\text { equivalent (Solids) }\end{array}$ & $\begin{array}{c}\text { Hydrochloric } \\
\text { acid-alcohol } \\
\text { ether method }\end{array}$ & $210 \pm 60$ & 264 \\
\hline Solid content (\%) & GB/1725 - 1989 & $60 \pm 2$ & 59.7 \\
\hline
\end{tabular}

The best mass ratio of the waterborne epoxy resin and the waterborne curing agent was turned out to be $0.7: 1$, which was verified by a surface curing time test on the glass plate and pencil hardness test. The ratio was used in all tests in this paper. 
Under this ratio, the waterborne epoxy resin was cured by the waterborne curing agent, and the curing reaction is shown in Equations (1) - (4). These formulas indicate that reaction between the epoxy group in the waterborne epoxy resin and the amine group in the curing agent produces secondary amine, tertiary amine, oxygen radical anion and network structure successively. The network structure is closely crosslinked to be the cured product. The morphology of the cured product was observed by the scanning electron microscope (SEM), shown in Figure 1. From Figure 1, continuous stratification of the cured product could be obviously seen, and strata were closely connected with each other. Besides, each stratum was extremely cohesive. Hence, changes of properties of emulsified asphalt by adding such a closely connected, cohesive stratified curing product were expected.

$\underset{\mathrm{O}}{\mathrm{H}_{2} \mathrm{C}} \underset{\mathrm{C}}{-\mathrm{CH}_{2}-}+\mathrm{R}-\mathrm{NH}_{2} \longrightarrow \mathrm{NH}-\mathrm{CH}_{2}-\underset{\mathrm{OH}}{\mathrm{CH}-}$,

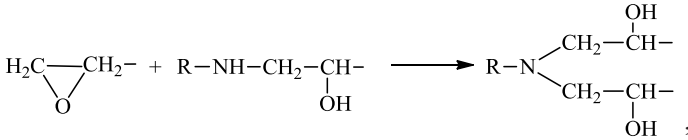

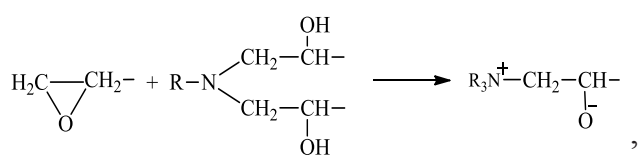

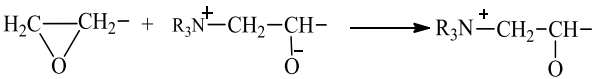

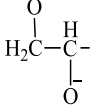

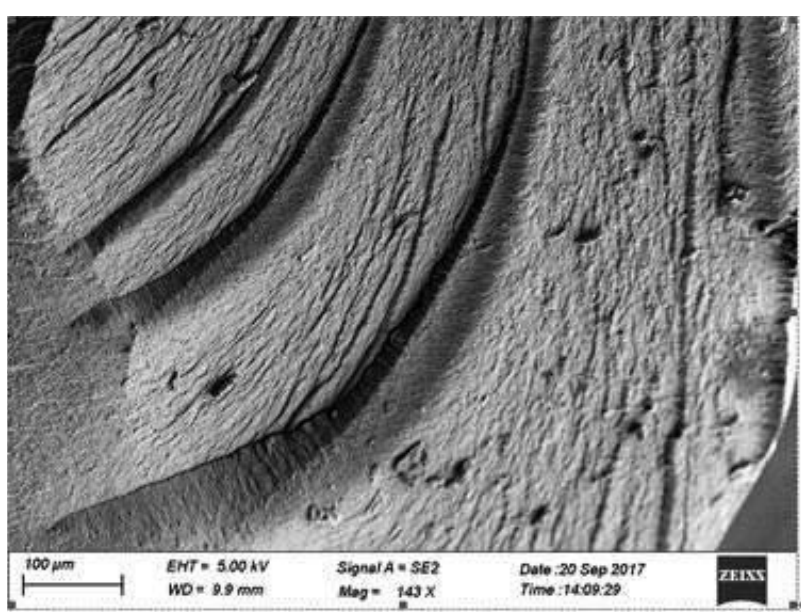

Figure 1. Closely connected, cohesive stratified morphology of cured waterborne epoxy resin.

The cationic emulsified asphalt (slow breaking, used for blending type) was used as received from the market with a solid content of $57.3 \%$ and the properties met the requirements of the Technical Specifications for Highway Asphalt Pavement Recycling (JTG F41-2008), China, which are shown in Table 3 .

Table 3. Properties of the slow breaking cationic emulsified asphalt.

\begin{tabular}{|c|c|c|c|}
\hline Content & Test method & Requirement & Test result \\
\hline $\begin{array}{c}\text { Surplus on sieve } \\
\text { (1.18 sieve) } \%\end{array}$ & $\mathrm{~T} 0651$ & $\leq 0.1$ & 0.03 \\
\hline $\begin{array}{c}\text { Adhesion on coarse } \\
\text { aggregate }\end{array}$ & $\mathrm{T} 0654$ & $\geq 2 / 3$ & $\geq 2 / 3$ \\
\hline Residue content, \% & $\mathrm{T} 0651$ & $\geq 55$ & 57.3 \\
\hline $\begin{array}{c}\text { Penetration }\left(25^{\circ} \mathrm{C}\right), \\
0.1 \mathrm{~mm}\end{array}$ & $\mathrm{~T} 0604$ & $45-150$ & 58.9 \\
\hline $\begin{array}{c}\text { Ductility (15\% } \mathrm{C}), \mathrm{cm} \\
\text { Solubility }\end{array}$ & $\mathrm{T} 0605$ & $\geq 40$ & 47.2 \\
\hline $\begin{array}{c}\text { (Trichloroethylene), } \\
\%\end{array}$ & $\mathrm{~T} 0607$ & $\geq 97.5$ & 98 \\
\hline $\begin{array}{c}1 \text { day storage } \\
\text { stability, \% }\end{array}$ & $\mathrm{T} 0655$ & $\leq 1$ & 0.2 \\
\hline $\begin{array}{c}1 \text { day storage } \\
\text { stability, \% }\end{array}$ & $\mathrm{T} 0655$ & $\leq 5$ & 1.2 \\
\hline
\end{tabular}

The waterborne epoxy emulsified asphalt was prepared referring to the principle of first emulsification and then modification process. The waterborne epoxy curing agent was mixed with the waterborne epoxy resin in the beaker with a prescribed ratio by the glass rod at a mixing speed of $120 \mathrm{r} / \mathrm{min}$ for one minute, and then the emulsified asphalt was poured into the beaker. The beaker was quickly moved under the lab multi-functional mixer (EDF-550). The mixing speed of the mixer was slowly adjusted to $300 \mathrm{r} / \mathrm{min}$ and the mixing continued for 10 minutes to make the system homogenously mixed.

\subsection{Methods}

\subsubsection{Fluorescent microscope}

As epoxy resin shows yellow green fluorescence, it is distinguishable among asphalt under the fluorescent microscope. Accordingly, the fluorescent microscope was used to observe the surface micromorphology of cured waterborne epoxy emulsified asphalt. Samples of waterborne epoxy emulsified asphalt were prepared according to the process mentioned earlier, and then uniformly coated on cleaned glass slides. After that, samples with glass slides were completely cured at $25^{\circ} \mathrm{C}$ for seven days, and the surface fluorescent micromorphologies of the samples were observed.

\subsubsection{Penetration and ductility of emulsion residue}

Two methods were used to characterise penetration and ductility of emulsion residue of waterborne epoxy 
emulsified asphalt. The results of three available specimens were recorded for one control test.

Method A (Normal method): According to T 0651-1993, T 0604-2011 and T 0605-2011 of the Standard Test Methods of Bitumen and Bituminous Mixtures for Highway Engineering (JTG E20-2011), China (hereinafter referred to as JTG E20-2011), penetration and ductility of emulsion residue of waterborne epoxy emulsified asphalt were tested. Before the tests, the waterborne curing agent was mixed with the waterborne epoxy resin and the emulsified asphalt just before the waterborne epoxy emulsified asphalt had been steamed. At the end of steaming, the sample was put into the oven at $163^{\circ} \mathrm{C}$ for one minute each time repeatedly, until the mass loss of the sample taken out from the oven and before put into the oven was less than $0.1 \%$.

Method B (Layering method): Samples of waterborne epoxy emulsified asphalt were poured into penetration mould by four layers and ductility mould by three layers. Height of the first three layers of penetration sample was $8 \mathrm{~mm}$ before each layer shrank due to the steamed water; the last layer was completely poured into the mould. The height of the first two layers of ductility sample was $5 \mathrm{~mm}$ before each layer shrank due to the steamed water and the last layer was completely poured into the mould too. After pouring each layer of sample, a sample with mould was put into a drying oven at $25^{\circ} \mathrm{C}$ for more than 24 hours, until the water content of the sample varied to less than $0.1 \%$ (the mass loss of the sample was less than $0.1 \%$ ), and then the next layer of sample could be poured onto the former cured sample. The same procedure as before was repeated. Then, until all layers of samples were moulded, penetration and ductility of samples were tested according to T 0604-2011 and T 0605-2011 of JTG E20-2011.

\subsubsection{Adhesion degree of casting resin}

According to the specification of GB 1720-79(89), China, the electric coat adhesion tester typed QFD was used to characterise the adhesion degree of cured waterborne epoxy emulsified asphalt coat. In this test, the adhesive base plane was tinplate $(50 \mathrm{~mm} \times 100 \mathrm{~mm} \times 0.2-0.3 \mathrm{~mm})$, and the waterborne epoxy emulsified asphalt was coated on the tinplate for more than 24 hours. No weight was added to the stylus, and the stylus was controlled to circle on the coat sample with a gyrated radius of $5.25 \mathrm{~mm}$. Then, many grids could be observed on the upper side of the coat sample, of which seven obvious grids were marked and then carefully observed. If more than $70 \%$ of one of the seven grids was intact, this grid would be considered to be intact. If all of seven grids were intact, the adhesion degree would be considered to be degree 1, while if six of seven grids were intact, and one was broken, that could be considered to be degree 2 and so on. Degree 7 was considered as the worst one. Three specimens were used for one control test. The QDF type electric coat adhesion tester and two typical tested samples (the cured waterborne epoxy resin and the cured waterborne epoxy emulsified asphalt) are shown in Figure 2, and the evaluating method of the adhesion degree is specified alongside.

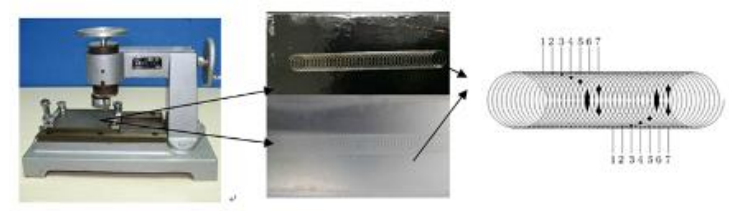

Figure 2. The adhesion degree tester and tested samples and its evaluating method.

\subsubsection{Shear strength}

The waterborne epoxy emulsified asphalt was gelatinised between two pieces of cleaned L-shaped steel mould, which were put into a drying oven at $25^{\circ} \mathrm{C}$ for more than 24 hours beforehand, with a bonding area of $40 \mathrm{~mm}$ $\times 34 \mathrm{~mm}$ and gelatinising content of $1.0 \mathrm{~kg} / \mathrm{m}^{3}$. Then the specimen was put into the $25^{\circ} \mathrm{C}$ drying oven again for 24 hours to make the waterborne epoxy emulsified asphalt cured completely. Before loading, in avoid of the interference of the torque, the geometrical centre of the specimen was calculated, and a vertical pressure force was loaded at the geometrical centre of the specimen to ensure the loading mode was pure shear, and then the moving speed of the pressure force was controlled as $50 \pm 5 \mathrm{~mm} / \mathrm{min}$ until the force gained at the experimental maximum value. On the bottom of the specimen, a piece of metal plate was cushioned to adjust the pressure force to be loaded at the geometrical centre of the specimen. The size of testing mould and specimen and the loading position are shown in Figure 3. The testing temperature was set at $2^{\circ} \mathrm{C}$. The results of the three available specimens were recorded for one control test. Shear strength was calculated using Equation (5).

$$
\tau=F s \times \sin \theta / S s=F s / S s\left(\theta=90^{\circ}, \sin \theta=1\right) .
$$

Where $F_{S}$ is the maximum experimental value of the pressure force, and $S S$ is the area of shearing plane, which is $40 \mathrm{~mm} \times 34 \mathrm{~mm}$.
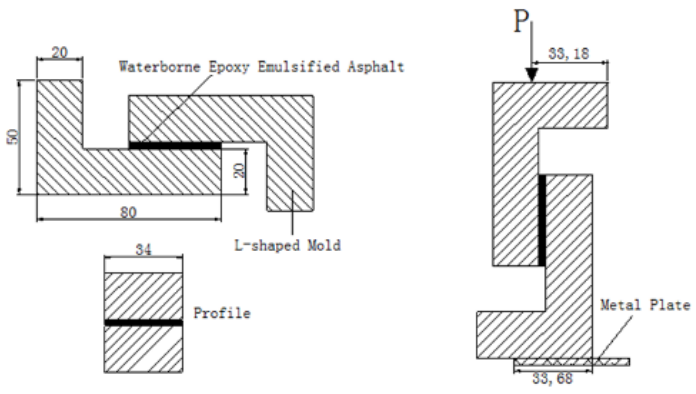

Figure 3. The size of testing mould and specimen and the loading position of shear strength. (Unit: $\mathrm{mm}$ ) 


\subsubsection{Bond strength}

The waterborne epoxy emulsified asphalt was gelatinised between two $\Phi 50 \mathrm{~mm}$ cores drilled from the asphalt pavement, with a gelatinising content of $0.6 \mathrm{~kg} / \mathrm{m}^{3}$, and a vertical tensile force was loaded to these two cores controlling the moving speed of the tensile force as $5 \mathrm{~mm} / \mathrm{min}$ until the force gained at the experimental maximum value. The specified testing mould and specimen are shown in Figure 4. The testing temperature was set at $25^{\circ} \mathrm{C}$. The results of the three available specimens were recorded for one control test. Bond strength was calculated using Equation (6).

$$
\sigma=F b / S b
$$

where $F b$ is the maximum experimental value of the tensile force, and $S b$ is the area of gelatinising plane, which is $\pi \times$ $25 \mathrm{~mm} \times 25 \mathrm{~mm}$.
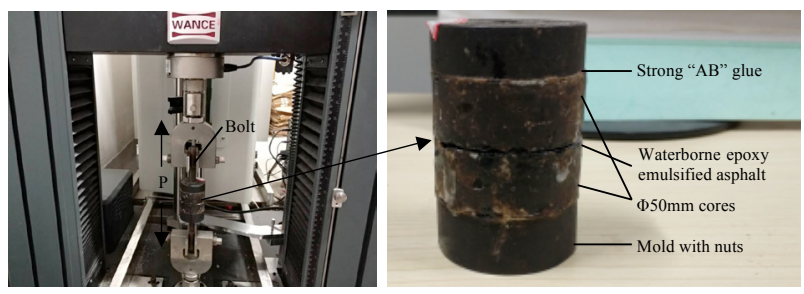

Figure 4. The testing mold and specimen of bond strength.

\subsubsection{Surface curing time of casting resin}

Referring to the specification of GB/T 13477.5-2002, China, the "finger contact method" was used to characterise surface curing time of waterborne epoxy emulsified asphalt. Waterborne epoxy emulsified asphalt was coated on two different substrate materials, which were tinplate and limestone, with the same coating weight of $0.6 \mathrm{~kg} / \mathrm{m}^{2}$. The size of tinplate was $50 \mathrm{~mm} \times 100 \mathrm{~mm} \times 0.2-0.3 \mathrm{~mm}$, and the limestone brick was incised from a rock block with a clean and flat surface, of which the area was about $100 \mathrm{~mm} \times 100 \mathrm{~mm}$. Before the test, the surface of both substrates were swept and then scrubbed by absolute ethyl alcohol. After that, the waterborne epoxy emulsified asphalt coat was contacted by a certain tester's finger for every 10 minutes, until the time point that the coat did not adhere to the finger and the time point was recorded as the surface curing time. Test samples on tinplate and limestone and the evaluating method of the surface curing time are shown in Figure 5. The test was conducted in a laboratory with relative humidity of $(50 \pm 5) \%$ and temperature of $25^{\circ} \mathrm{C}$. The results of the three available specimens were recorded for one control test.

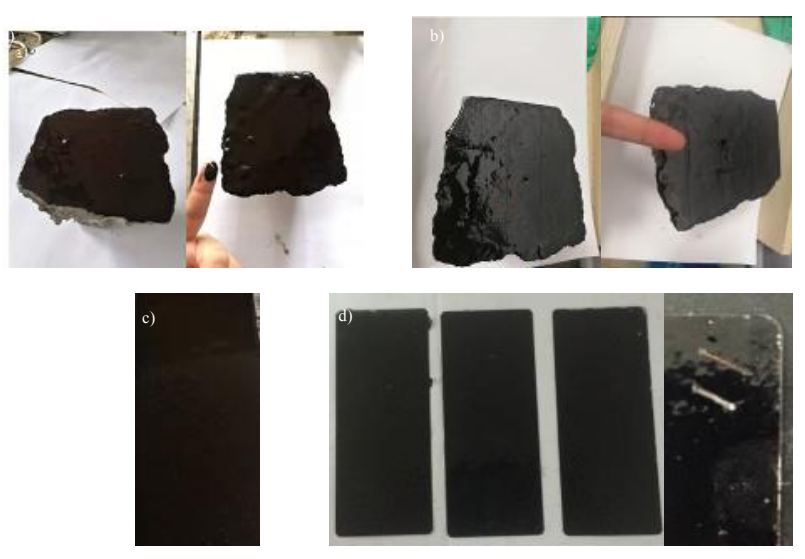

Figure 5. Test samples on tinplate and limestone before and after the surface curing time (a) on limestone and before curing; (b) on limestone and cured; (c) on tinplate and before cuirng; and (d) on tinplate and cured.

\section{Results and discussion}

\subsection{Effect of waterborne epoxy resin on surface fluorescent micromorphology of cured waterborne epoxy emulsified asphalt}

At an identical magnification of 100 times, surface fluorescent micro-morphologies of the cured waterborne epoxy emulsified asphalt, containing $0 \%, 10 \%, 20 \%$, $30 \%$ of waterborne epoxy resin respectively, are shown in Figure 6 . The images show obvious morphological change as the content of waterborne epoxy resin increases. For $0 \%$ waterborne epoxy resin content, the micrograph is totally black because there is no epoxy resin distributed in non-fluorescent asphalt. For 10\% waterborne epoxy resin content, epoxy resin particles are distributed among the asphalt as spotted status, which means particles are segregated into small spots as the discrete phase. For $20 \%$ waterborne epoxy resin content, some particles become closer as clustered status and the sizes of some particles enlarge. The cause of the enlarging phenomenon was concluded by Kang et al. (2015) as the chemical gelation process. Accordingly, the chemical gelation is more sufficient as the content of waterborne epoxy resin increases. Moreover, similar to the morphology of epoxy asphalt studied by Yu et al. (2009), in Figure 6(c), some of the epoxy resin and asphalt are continuous and interlocked, and the epoxy resin phase gradually becomes a continuous phase. For $30 \%$ waterborne epoxy resin content, most of epoxy resin particles connect and a majority of epoxy resin phase forms a continuous phase. However, for the asphalt phase is also connected, the morphology could be considered as a peculiar "two-phase co-continuous structure" (Isabel and Andrew, 1988). "Two-phase cocontinuous structure" is commonly seen in phase-separated polymer blends, of which each phase in the polymer blend is continuous. The main form of "two-phase co-continuous 
structure" in polymer blends is the "interpenetrated network" (IPN) (Wu et al., 2015). IPN structure of polymer blends forms if one polymer network is synthesised or cross-linked independently in the presence of another polymer without any covalent bonds between them (Wu et al., 2015). Accordingly, the peculiarity of the "two-phase co-continuous structure" shown in Figure 6(d) is that IPN does not form in waterborne epoxy emulsified asphalt because the asphalt is not as cross-linked as the epoxy resin.
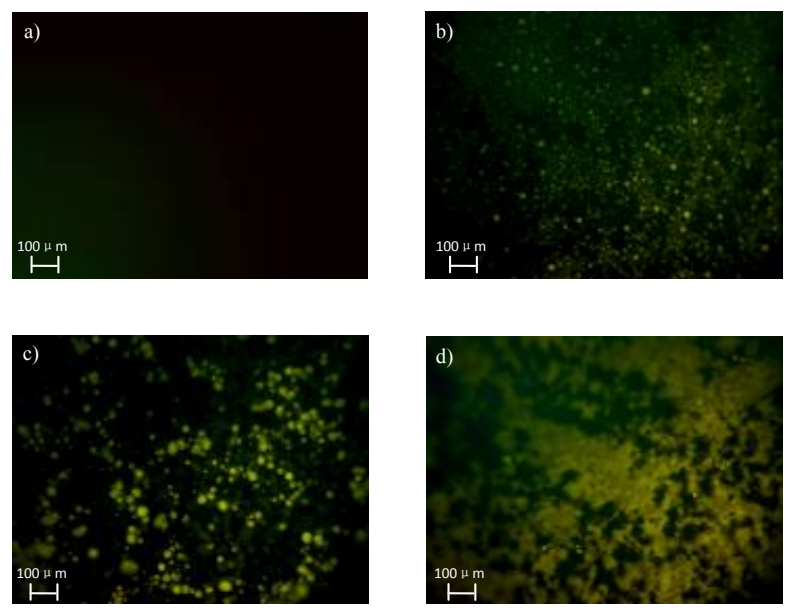

Figure 6. Surface fluorescent micro-morphologies of cured waterborne epoxy emulsified asphalt containing waterborne epoxy resin content of a) $0 \%$; b) $10 \%$; c) $20 \%$; and d) $30 \%$.

\subsection{Effect of waterborne epoxy resin on penetration and ductility of waterborne epoxy emulsified asphalt}

Seven contents of waterborne epoxy resin, which were $0 \%, 5 \%, 10 \%, 15 \%, 20 \%, 25 \%$ and $30 \%$, were chosen for a penetration test on the waterborne epoxy emulsified asphalt with samples prepared by the above two methods, and five contents $(0 \%, 5 \%, 10 \%, 15 \%$ and $20 \%)$ were chosen for ductility test. Test results are shown in Figures 7 and 8 .

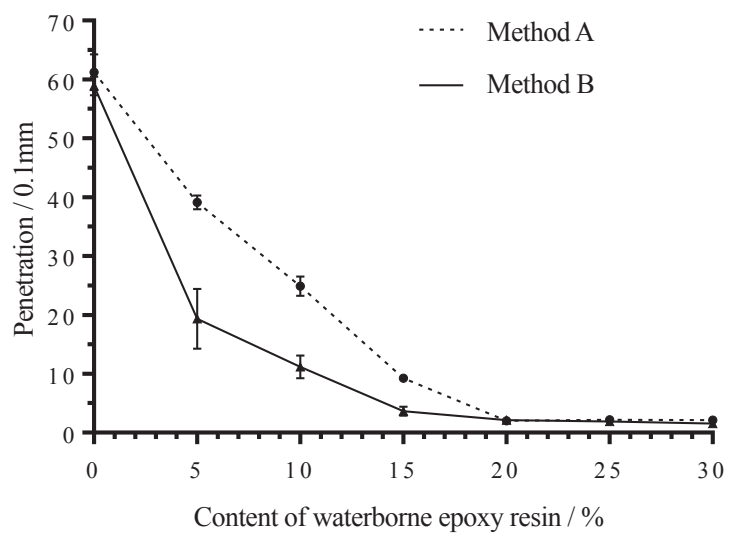

Figure 7. Effect of waterborne epoxy resin content on penetration of emulsified asphalt residue.

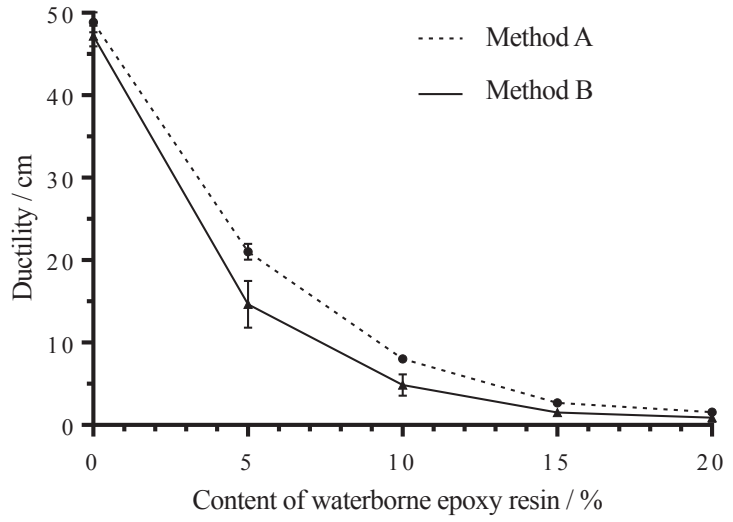

Figure 8. Effect of waterborne epoxy resin content on ductility of emulsified asphalt residue.

It can be seen in Figures 7 and 8 that the difference of test results by the two methods is remarkable. The results of penetration and ductility of samples prepared by Method A are both obviously smaller than the results of the samples prepared by Method B. It is because, differed from Method B, in Method A, waterborne epoxy emulsified asphalt is steamed at a higher temperature. As deduced from the curing reaction model of epoxy resin proposed by Qian et al. (2012), the reaction convert degree of epoxy resin increases with the increase in reaction temperature, which is illustrated by the test results of isothermal reaction kinetics studied by Kenny and Trivisano (1991). Generally, higher reaction convert degree of epoxy resin leads to a higher crosslinking degree or more crosslinking networks formed from the reaction between epoxy resin and curing agent, which enhance the restriction of the relative movement of asphalt particles (Zhang and He, 2007), and then evaporated residue samples are more difficult to be penetrated by the test needle, and easier to be snapped by the tensile force. Accordingly, the preparing temperature of penetration samples and ductility samples of waterborne epoxy emulsified asphalt influences test results. Since the waterborne epoxy emulsified asphalt is used for cold patch, with the applied temperature closer to the room temperature, Method B is recommended, of which the preparing temperature of test samples is more similar to the applied temperature in real engineering.

Moreover, from the test results of the samples prepared by Method B shown in Figures 7 and 8, it can be seen that, when the content of waterborne epoxy resin is less than $20 \%$, with its increase, both the penetration and ductility of waterborne epoxy emulsified asphalt decrease. As deduced from the study of Zhang et al. (2017), when the content of epoxy resin is larger than $3 \%$, with its increasing content, the three-dimensional network skeleton with irreversible chemical bonds formed by cured products becomes more densely distributed in waterborne epoxy emulsified asphalt, and the displacement of asphalt molecules becomes more retarded. Consequently, smaller deformation is allowed, 
and penetration samples and ductility samples become harder and more brittle. As studied by Zhang and He (2007), the concentration of waterborne epoxy resin in asphalt will increasingly get high along with the increasing amount of waterborne epoxy resin, which is identical to the earliermentioned surface fluorescent micro-morphologies of waterborne epoxy emulsified asphalt in this paper. For instance, along with the increasing content of waterborne epoxy resin from $0 \%$ to $10 \%$, the concentration of epoxy resin particles gets higher and the network segments formed by cured products increase. These network segments provide resistance to external forces (Zhang and He, 2007), including the resistance to the penetrating force of the needles and the tensile force, so penetration and ductility of waterborne epoxy emulsified asphalt decrease remarkably. When the content of waterborne epoxy resin increases from $10 \%$ to $20 \%$, as mentioned earlier, the epoxy resin phase gradually becomes a continuous phase and properties of samples become being mainly determined by the epoxy resin (Yu et al., 2009). The epoxy resin is a thermosetting material with much higher hardness than asphalt, so the penetration and ductility keep decreasing to be very small. Furthermore, because some of the epoxy resin phase has already become the continuous phase when the content is $20 \%$, so if the content of waterborne epoxy resin keeps increasing from $20 \%$, the penetration will remain unchangeable.

\subsection{Effect of waterborne epoxy resin on adhesion degree, shear strength and bond strength of waterborne epoxy emulsified asphalt}

Four contents of waterborne epoxy resin were chosen for the adhesion degree test of waterborne epoxy emulsified asphalt, which were $0 \%, 10 \%, 20 \%$ and $30 \%$, and five contents were chosen for a shear strength test and a bond strength test, which were $0 \%, 5 \%, 10 \%, 20 \%$ and $30 \%$.

Each test result of the adhesion degree of three specimens of waterborne epoxy emulsified asphalt with the same content of waterborne epoxy resin was the same and the results are shown in Table 4 . From Table 4 it can be seen, when the content of waterborne epoxy resin in the emulsified asphalt is less than $20 \%$, the adhesion degree of waterborne epoxy emulsified asphalt increases with the increasing content of waterborne epoxy resin; but when the content of waterborne epoxy resin in the emulsified asphalt reaches $20 \%$, the adhesion degree of waterborne epoxy emulsified asphalt has already reached the highest, which is degree 1 .

Table 4. Effect of waterborne epoxy resin content on adhesion degree of emulsified asphalt coat.

\begin{tabular}{cccccc}
\hline $\begin{array}{c}\text { Content of waterborne epoxy resin in } \\
\text { waterborne epoxy emulsified asphalt (\%) }\end{array}$ & 0 & 10 & 20 & 30 \\
\hline Adhesion (degree) & 7 & 3 & 1 & 1 \\
\hline
\end{tabular}

It can be seen from the results of the shear strength test and bond strength test in Figure 9 that, with the increase in content of waterborne epoxy resin, both shear strength and bond strength of waterborne epoxy emulsified asphalt increase, while if the content of waterborne epoxy resin is among $10 \%$ - $20 \%$, the increasing range is remarkable, especially for shear strength.

The changing trend could also be illustrated by the micromorphology of waterborne epoxy emulsified asphalt. Similar to the study of Ding et al. (2011), with the waterborne epoxy resin, the surface of asphalt becomes rough and the spatial structure is strengthened. The crosslinking of the cured products enhances the adhesive force of waterborne epoxy emulsified asphalt and reinforces asphaltic material to make the shear resistance superior. When the content of waterborne epoxy resin is less than $10 \%$, as mentioned earlier, epoxy resin particles are distributed in the asphalt as the discrete phase (Yu et al., 2009), and networks formed by cured products do not get connected. Consequently, the enhancement of bond strength of waterborne epoxy resin on the emulsified asphalt is limited, and the segregated epoxy resin particles as the discrete phase (Yu et al., 2009) provide limited resistance to the shear force; additionally, because the adhesion degree of cured emulsified asphalt without waterborne epoxy resin is degree 7 , which means the cured pure emulsified asphalt can resist no scratching force at all and regions of emulsified asphalt that are not distributed by epoxy resin particles is incapable of resisting the scratching force, and consequently the adhesion degree merely reaches degree 3 .

When the content of waterborne epoxy resin increases to $20 \%$, for some of the cured waterborne epoxy resin becomes continuous phase, properties of waterborne epoxy emulsified asphalt are mainly determined by epoxy resin as mentioned earlier. The stiffness of the cured waterborne epoxy resin ensures enough anti-scratch performance in waterborne epoxy emulsified asphalt, which indicates obvious adhesion enhancement (from degree 3 to degree 1) of waterborne epoxy emulsified asphalt. Accordingly, the bond strength of waterborne epoxy emulsified asphalt increases remarkably. Besides, because the three-dimensional network skeleton of the cured waterborne epoxy resin (Zhang et al., 2017) enhances the restriction of relative movement of asphalt particles (Zhang and He, 2007), the shear strength of waterborne epoxy emulsified asphalt increases remarkably too. When the content of waterborne epoxy resin increases to $30 \%$, more cured waterborne epoxy resin particles take part in the formation of continuous phase, so that properties of epoxy resin present more in waterborne epoxy emulsified asphalt. That is the reason why bond strength and shear strength of waterborne epoxy emulsified asphalt increase further. However, since some of epoxy resin particles have already taken part in the formation of a continuous phase when the content of waterborne epoxy resin is $20 \%$, the increase 
in bond strength and shear strength of waterborne epoxy emulsified asphalt is no longer remarkable when the content of waterborne epoxy resin increases from $20 \%$ to $30 \%$. Besides, the adhesion degree remains unchanged as degree 1.

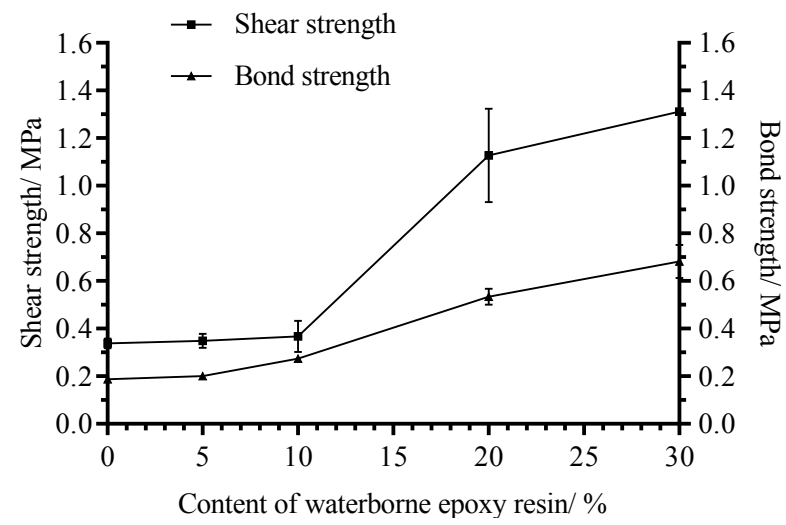

Figure 9. Effect of waterborne epoxy resin content on shear strength and bond strength of waterborne epoxy emulsified asphalt.

\subsection{Effect of waterborne epoxy resin on surface curing time of waterborne epoxy emulsified asphalt}

Contents of waterborne epoxy resin for the surface curing time test were chosen as $0 \%-24 \%$, with the interval of $3 \%$. The results are shown in Figure 10. It can be seen in Figure 10 that, with the increase in the content of waterborne epoxy resin, the surface curing time of waterborne epoxy emulsified asphalt on both of these two substrate materials decreases.

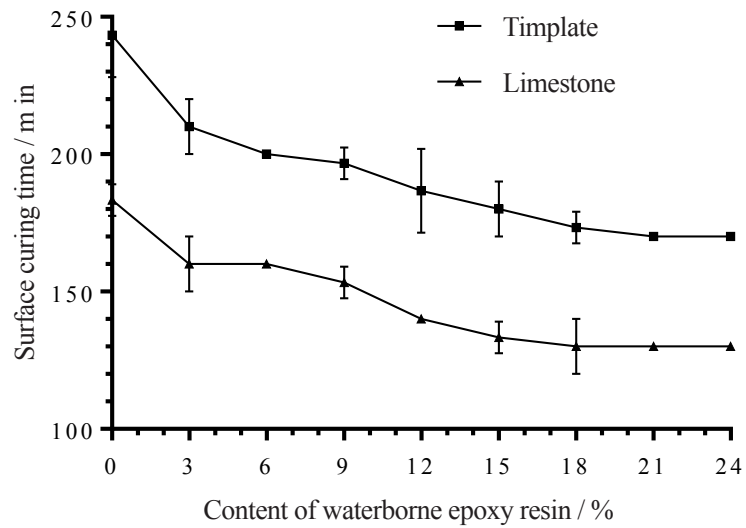

Figure 10. Effect of waterborne epoxy resin content on surface curing time of emulsified asphalt coat.

The decreasing trend is caused by the curing reaction of the waterborne epoxy resin. It is easily seen from Equations (1) - (4) that the reaction between the waterborne epoxy resin and the waterborne curing agent is simply the additive reaction between an epoxy group and an amino group, neglecting the side reaction of self-polymerisation of epoxy group (Kamon and Furukawa, 2006; Riccardi and William, 1986) and the difference between an activity of secondary amine and tertiary amine in the curing agent from the epoxy group (Catalani and Bonicelli, 2005). From the differential scanning calorimetry (DSC) curves of the reaction between the epoxy group and the amino group (Yu et al., 2009), it can be seen that the reaction is an exothermic reaction. The heats released from the reaction accelerate the evaporation of water in waterborne epoxy emulsified asphalt, so larger content of waterborne epoxy resin produces more heats released from the reaction, and consequently the evaporation of water in waterborne epoxy emulsified asphalt is faster. Therefore, the surface curing time decreases.

\section{Conclusions}

Through the tests of fluorescent microscope, penetration and ductility of emulsion residue, adhesion degree of casting resin, shear strength, bond strength and surface curing time of casting resin, effects of phaseinversion waterborne epoxy resin on waterborne epoxy emulsified asphalt were studied. The main conclusions are drawn as follows:

(1) Phase-inversion waterborne epoxy resin influences the surface fluorescent micromorphology of cured waterborne epoxy emulsified asphalt. With the increase in the waterborne epoxy resin content from $0 \%$ to $30 \%$, firstly, epoxy resin particles are distributed among the emulsified asphalt as spotted discrete phase and some network segments form, and then some epoxy resin particles become closer as clustered status and gradually become a continuous phase, which restrict the relative movement of asphalt particles. Finally, more and more epoxy resin particles connect and "two-phase co-continuous structure" of waterborne epoxy emulsified asphalt forms.

(2) The effect of phase-inversion waterborne epoxy resin on the micromorphology of waterborne epoxy emulsified asphalt reflects on its properties. When the waterborne epoxy resin content increases from $0 \%$ to $10 \%$, the enhancement of shear strength and bond strength of waterborne epoxy emulsified asphalt is limited, but the penetration and ductility decrease remarkably. When its content increases from $10 \%$ to $20 \%$, properties are mainly determined by the epoxy resin so that the penetration and ductility keep decreasing to be very small, while the adhesion degree reaches the highest and the bond strength and shear strength increase remarkably. When its content keeps increasing from $20 \%$ to $30 \%$, the adhesion degree and penetration remain unchanged, and the increase in bond strength and shear strength is no longer remarkable. Therefore, the recommended waterborne epoxy resin content is $20 \%$. 
(3) Penetration and ductility test values of samples prepared by the "layering method" are both obviously larger than those by the "normal method". Nevertheless, according to the applied temperature in real engineering, the "layering method" is recommended to prepare penetration and ductility samples of waterborne epoxy emulsified asphalt.

(4) Because of the exothermic reaction between waterborne epoxy resin and waterborne curing agent, the surface curing time of waterborne epoxy emulsified asphalt decreases with the increase in content of waterborne epoxy resin.

\section{Acknowledgements}

This study was conducted under a grant from a programme supported by the Ministry of Transport, the People's Republic of China. The programme is the "Scientific and Technologic program for the construction of western transportation". The grant number is 2014318346 140.

\section{Notes on Contributors}

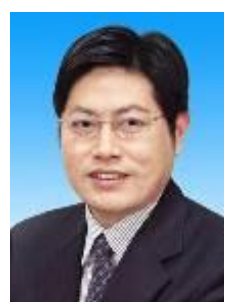

Prof Boming Tang is a professor in the School of Civil Engineering at Chongqing Jiaotong University (CQJTU) in Chongqing, China. Prof Tang is also President of CQJTU, Deputy Director of the China Highway and Transportation Society, Vice President of the Chongqing Association of Science and Technology, and an Adjunct Professor in the College of Transportation Engineering at Tongji University (TJU) in Shanghai, China.

He received his B.Sc. degree in Road Engineering and Ph.D. in Road and Traffic Engineering from Southeast University in Nanjing, China. Upon completing the Ph.D., he worked as a postdoctoral researcher and then an Associate Professor at TJU. After that, he worked as an Associate Professor at Nagaoka University of Technology in Nagaoka, Japan. Then he worked as a Vice President and a Professorate Senior Engineer at the Chongqing Highway Bureau and the Chongqing Transport Commission. He later on joined CQJTU as President, and founded the Prof Boming Tang Research Group. His research interests include roadbed and pavement engineering, pavement materials, and the theory and technology of road traffic safety.

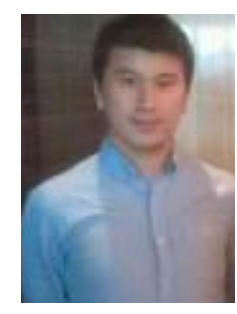

Mr Yu Gu is a Ph.D. candidate in the College of Transportation Engineering at TJU. He received his B.Sc. degree in Civil Engineering from Hunan University in Hunan, China and M.Sc. degree in Transportation Engineering from CQJTU. His research interests include modified materials for pavements, waterborne epoxy materials for pavements, recycled materials for the asphalt pavement and image processing technology for pavement materials.

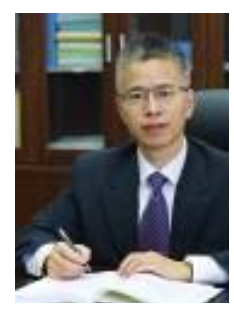

Prof Jianming Ling is a Professor in the College of Transportation Engineering at TJU. Prof Ling is also the Dean of the College.

He received his B.Sc. degree in Railway Engineering and M.Sc. degree in Geotechnical Engineering from Southwest Jiaotong University in Chengdu, China. He also graduated with a Ph.D. in Structural Engineering from TJU. Upon completing the Ph.D., he worked as a postdoctoral researcher and then a Professor at TJU. His research interests include roadbed engineering and airport engineering.

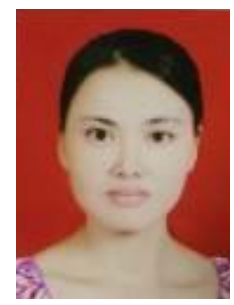

Dr Lihong He is a Professor in the School of Civil Engineering at the CQJTU. She received her B.Sc. degree in Polymer Materials and M.Sc. degree in Materials Science from The Wuhan University of Technology in Wuhan, China. Then she obtained her Ph.D. in Pavement Engineering from CQJTU. Her research interests include modified materials for pavements, phase change material and resin modification.

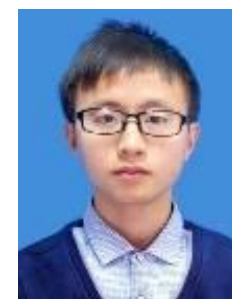

Mr Fan Yang is a doctoral student in the College of Transportation Engineering at TJU. He received his B.Sc. degree in Applied Chemistry and M.Sc. degree in Material Science and Engineering from CQJTU. His research interests include waterborne epoxy materials for pavements, phase change material for pavements and polyurethane materials for pavements. 


\section{References}

[1] Abd El-Rahman AMM, El-Shafie M, Abo-Shanab ZL and El-Kholy SA (2017). Modifying asphalt emulsion with different types of polymers for surface treatment applications. Petroleum Science and Technology, 35(14), pp. 1473-1480.

[2] Al-Sabagh AM (2002). The relevance HLB of surfactants on the stability of asphalt emulsion. Colloids and Surfaces A: Physicochemical and Engineering Aspects, 204(1), pp. 73-83.

[3] Catalani A and Bonicelli MG (2005). Kinetics of the curing reaction of a diglycidyl ether of bisphenol A with a modified polyamine. Thermochimica Acta, 438(1), pp. 126-129.

[4] Chen ZF and Chen ZD (2016). Study on mix proportion design of epoxy emulsified asphalt mixture. In: Proceedings of the 1st International Conference on Transportation Infrastructure and Materials. Xi'an: DEStech Transactions on Engineering and Technology Research, pp. 194-201.

[5] Ding QJ, Shen F, Sun Z and Huang SL (2007). Development and conceptual design of steel deck pavement used cement emulsified-asphalt epoxy resin concrete. In: Proceedings of the International Conference on Advanced Engineering Materials and Technology. Kunming: Advanced Materials Research, pp. 287-290.

[6] Ding QJ, Shen F, Sun Z and Huang SL (2011). A laboratory investigation into the composite bonding system of cement-emulsified asphalt-epoxy resin. Applied Mechanics and Materials, 80-81, pp. 379384.

[7] Isabel SM and Andrew Z (1988). Preparation, structure, and properties of two-phase co- continuous polymer blends. Polymer Engineering and Science, 28(12), pp. 796-805.

[8] Kamon T and Furukawa H (2006). Curing mechanisms and mechanical properties of cured epoxy resins. Advances in Polymer Science, 80, pp. 173-202.

[9] Kang Y, Song MY, Pu L and Liu TF (2015). Rheological behaviors of epoxy asphalt binder in comparison of base asphalt binder and SBS modified asphalt binder. Construction and Building Materials, 76, pp. 343-350.

[10] Kenny JM and Trivisano A (1991). Isothermal and dynamic reaction kinetics of high performance epoxy matrices. Polymer Engineering and Science, 31(19), pp. 1426-1433.

[11] Qian ZD, Chen LL, Wang YQ and Shen JL (2012). Curing reaction model of epoxy asphalt binder. Journal of Wuhan University of Technology: Materials Science Edition, 27(4), pp. 763-767.
[12] Riccardi CC and William RJJ (1986). A kinetic scheme for an amine-epoxy reaction with simultaneous etherification. Journal of Applied Polymer Science, 32(2), pp. 3445-3456.

[13] Shen F, Huang SL, Sun Z and Ding QJ (2012). Research on hardening mechanism of cementemulsified asphalt-epoxy resin. Advanced Materials Research, 430-432, pp. 434-437.

[14] Wu H, Zhu MJ, Liu Z and Yin J (2015). Developing a polymer-based crack repairing material using interpenetrate polymer network (IPN) technology. Construction and Building Materials, 84, pp. 192-200.

[15] Yang ZZ, ZhuY, Dong Q and Bu HT (2001). Sub-micron-sized waterborne particles of crosslinked epoxy resin prepared by phaseinversion emulsification. Macromolecular Rapid Communications, 22, pp. 792-796.

[16] Yu JY, Cong PL and Wu SP (2009). Laboratory investigation of the properties of asphalt modified with epoxy resin. Journal of Applied Polymer Science, 113(6), pp. 3557-3563.

[17] Yu JY, Cong PL, Wu SP and Cheng SB (2009). Curing behavior of epoxy asphalt. Journal of Wuhan University of Technology: Materials Science Edition, 24(3), pp. 462-465.

[18] Zhang P (2005). Defence methods for reflective cracks in existed cement concrete black pavement. Journal of Chang'An University: Natural Science Edition, 25(03), pp. 16-18, 62.

[19] Zhang RH and He YH (2007). An asphalt emulsion modified by compound of epoxy resin and styrenebutadiene rubber emulsion. In: Proceedings of the 9th WSEAS International Conference on Mathematical and Computational Methods in Science and Engineering. Trinidad and Tobago: International Journal of Mathematical Models and Methods in Applied Sciences, pp. 291-297.

[20] Zhang ZY, Huang YH, Liao B and Cong GM (2001). Studies on particle size of waterborne emulsions derived from epoxy resin. European Polymer Journal, 37, pp. 1207-1211.

[21] Zhang Q, Xu YH and Wen ZG (2017). Influence of water-borne epoxy resin content on performance of waterborne epoxy resin compound SBR modified emulsified asphalt for tack coat. Construction and Building Materials, 153, pp. 774-782. 